\title{
Assessing Short-term Deterioration in Maintenance- naïve Patients with COPD Receiving Umeclidinium/ Vilanterol and Tiotropium: A Pooled Analysis of Three Randomized Trials
}

\author{
M. Reza Maleki-Yazdi · Dave Singh · Antonio Anzueto · Lee Tombs • \\ William A. Fahy · Ian Naya
}

Received: August 25, 2016 / Published online: October 28, 2016

(C) The Author(s) 2016. This article is published with open access at Springerlink.com

\begin{abstract}
Introduction: Dual bronchodilator therapy is reserved as a second-line treatment in patients with chronic obstructive pulmonary disease (COPD) and provides benefits in lung function and health status versus monotherapy. The aim of this study was to determine whether early initiation of a dual bronchodilator versus
\end{abstract}

These results were presented in part at the European Respiratory Society Annual Congress, Amsterdam, The Netherlands, 26-30 September 2015.

Enhanced content To view enhanced content for this article go to http://www.medengine.com/Redeem/ D117F06009F8C122.

Electronic supplementary material The online version of this article (doi:10.1007/s12325-016-0430-6) contains supplementary material, which is available to authorized users.

M. R. Maleki-Yazdi ( $\square)$

Division of Respiratory Medicine, Women's College

Hospital, University of Toronto, Toronto, ON,

Canada

e-mail: maleki.pccrc@on.aibn.com

D. Singh

Medicines Evaluation Unit, University of

Manchester, University Hospital of South

Manchester Foundation Trust, Manchester, UK monotherapy reduced the risk of deterioration in COPD.

Methods: This post hoc pooled analysis investigated the efficacy and safety of umeclidinium/vilanterol (UMEC/VI) 62.5/ $25 \mathrm{mcg} /$ day compared with tiotropium (TIO) $18 \mathrm{mcg} /$ day in a maintenance-naïve (MN) subgroup of patients relative to the intent-to-treat (ITT) population from three 6 -month active comparator studies $(n=1747)$. Other treatment arms (UMEC/VI 125/25, VI 25 and UMEC 125) comprised 850 patients in total but were not included in this analysis. The primary endpoint was trough forced expiratory volume in $1 \mathrm{~s}\left(\mathrm{FEV}_{1}\right)$. St George's Respiratory Questionnaire (SGRQ) score, rescue medication use, and a novel composite endpoint of short-term clinically important deterioration (CID; $\geq 100 \mathrm{ml}$ decrease in trough $\mathrm{FEV}_{1}$,
A. Anzueto
South Texas Veterans Health Care System, Audie L.
Murphy Hospital, and University of Texas Health
Science Center, San Antonio, TX, USA
L. Tombs
Precise Approach LTD, Birmingham, UK
W. A. Fahy · I. Naya
GSK, Respiratory Medicines Development Centre, Stockley Park, Middlesex, UK 
24-unit increase in SGRQ score, or a COPD exacerbation) were also assessed.

Results: UMEC/VI improved trough $\mathrm{FEV}_{1}$ versus TIO at day 169 [least squares mean (95\% confidence interval): $\mathrm{MN}: 146 \mathrm{ml}$ (102-189) and ITT: $95 \mathrm{ml}$ (71-118); both $P<0.001]$. Both UMEC/VI and TIO improved SGRQ and rescue use in the two populations, with greater improvements in rescue use with UMEC/VI versus TIO. UMEC/VI reduced the risk of short-term clinically important deterioration versus TIO [hazard ratio; 95\% confidence interval: $\mathrm{MN}: 0.66$ (0.51-0.85); ITT: 0.62 (0.54-0.71), both $P \leq 0.001]$. Adverse events were similar across both populations and treatments.

Conclusions: Early use of dual-bronchodilator therapy has superior efficacy on lung function and may reduce the risk of short-term deterioration compared to monotherapy in symptomatic patients with COPD.

Clinical trial registration: GSK analysis 202066 (NCT01316900/DB2113360, NCT01316913/ DB2113374, NCT01777334/ZEP117115).

Funding: This study was funded by GSK.

Keywords: Chronic obstructive pulmonary disease; Clinically important deterioration; Respiratory; Umeclidinium; Vilanterol

\section{INTRODUCTION}

There is evidence to suggest that early initiation of maintenance bronchodilator therapy in patients with chronic obstructive pulmonary disease (COPD) may provide benefits in lung function and health status [1-3]. A recent study also reported that dual-bronchodilator maintenance therapy with a long-acting muscarinic antagonist (LAMA) plus a long-acting $\beta_{2}$-agonist (LABA) may provide improvements in lung function in treatment-naïve patients and patients with less severe COPD, as well as those already receiving maintenance therapy [4].

Since many patients with COPD with moderate lung function impairment remain symptomatic with mono-bronchodilator therapy [5], a rationale for the use of dual bronchodilators in these patients is emerging. The effects of early initiation of maintenance therapy with long-acting bronchodilators are not yet fully characterized, and fundamental questions remain regarding the most appropriate timing of maintenance bronchodilator therapy initiation for COPD and which patients would benefit most from dual-bronchodilator treatment versus monotherapy. To assess these points it is important to consider not just improvements but also the risk of deterioration in both lung function and health status in COPD with dual-bronchodilator versus standard LAMA monotherapy when used as either first- or second-line therapy.

Short-term clinically important deterioration (CID) is a new composite endpoint in COPD, which encompasses the occurrence of clinically significant, recognized deteriorations (termed minimal clinically important differences) in lung function, quality of life (QoL), and moderate-to-severe exacerbations that can be used as a measure of disease worsening [6-9]. This composite endpoint is consistent with current Global initiative for chronic Obstructive Lung Disease (GOLD) guidelines [10], which recommend that lung function, health status, and COPD exacerbation risk are considered when assessing disease progression and severity. There are currently limited objective means to assess symptomatic patients at an early stage in the course of COPD; therefore, assessment of CID may 
provide useful information on how to maintain patient stability and prevent deterioration.

The objective of this pooled analysis was to compare the efficacy of the LAMA/LABA combination, umeclidinium/vilanterol (UMEC/ VI), and the widely used LAMA, tiotropium (TIO), in a subgroup of maintenance-naïve (MN) patients relative to a larger intent-to-treat (ITT) population, based on lung function, health-related QoL (HRQoL), rescue medication use, and prevention of CID in patients with COPD and moderate-to-severe breathlessness.

\section{METHODS}

\section{Study Design, Treatments, and Patients}

This was a post hoc analysis (GSK analysis: 202066) of data from three multicenter, randomized, 24-week, parallel-group, blinded trials selected because they compared UMEC/VI and TIO: ZEP117115 (NCT01777334) [11], DB2113374 (NCT01316913) [12], and DB2113360 (NCT01316900) [12].

Patients were randomized to receive once-daily inhaled UMEC/VI 62.5/25 mcg (delivering $55 \mathrm{mcg}$ and $22 \mathrm{mcg}$, respectively) via the ELLIPTA ${ }^{\mathrm{TM}}$ dry powder inhaler or TIO 18 mcg via the HandiHaler ${ }^{\circledR}$. Studies DB2113360 and DB2113374 also included treatment arms for once-daily UMEC/VI 125/25 mcg (delivering $113 \mathrm{mcg}$ and $22 \mathrm{mcg}$ ) and either VI $25 \mathrm{mcg}$ (DB2113360) or UMEC 125 mcg (DB2113374). Data were included in the analysis, but results are not presented in this manuscript [11, 12].

Patients were aged $\geq 40$ years, had a diagnosis of symptomatic COPD [13], a modified Medical Research Council Dyspnea Scale score $\geq 2$ (i.e., all patients had moderate-to-severe breathlessness), had a post-bronchodilator forced expiratory volume in $1 \mathrm{~s}\left(\mathrm{FEV}_{1}\right)$ of $\leq 70 \%$ predicted, and an $\mathrm{FEV}_{1} /$ forced vital capacity ratio $<0.70$. Patients were excluded if they had a current diagnosis of asthma or other known respiratory condition.

All procedures followed in the studies were in accordance with the ethical standards of the responsible committee on human experimentation (institutional and national) and with the Helsinki Declaration of 1964, as revised in 2013. Informed consent was obtained from all patients for being included in the studies.

\section{Outcomes and Assessments}

The primary endpoint in all studies was change from baseline in trough $\mathrm{FEV}_{1}$ on day 169, defined as the mean of the $\mathrm{FEV}_{1}$ values obtained 23 and $24 \mathrm{~h}$ after dosing on day 168 . St George's Respiratory Questionnaire (SGRQ) total score was assessed in each study. SGRQ responders were defined as patients who experienced a decrease from baseline of $\geq 4$ units [6]. Daily use of rescue medication was also assessed. As a minimal clinically important difference for rescue medication use is not yet defined, we pre-specified a treatment benefit of 1 rescue-free month per year or 2 rescue-free weeks out of 24 (corresponding to a change from baseline $\geq 8.3 \%$ in the percentage of rescue-free days over weeks 1-24) as clinically important and used this value as the definition of rescue medication responders.

This analysis was performed on a subgroup of $\mathrm{MN}$ patients (defined as receiving no maintenance therapy for $\geq 30$ days before screening) and the ITT population and assessed the time to, and risk of, a short-term CID. CID was defined as: a decrease from 
baseline of $\geq 100 \mathrm{ml}$ in trough $\mathrm{FEV}_{1}$ [9], and/or an increase from baseline of $\geq 4$ units in SGRQ total score [6], and/or an on-treatment moderate-to-severe COPD exacerbation (defined as a worsening of COPD symptoms requiring use of any additional treatment other than study drug or rescue albuterol use and an emergency department visit or hospitalization). Deteriorations in trough $\mathrm{FEV}_{1}$ were assessed based on data from seven trial visits post-randomization (days 2, 28, 56, 84, 112, 168 , and 169) and SGRQ from three study visits (days 28, 84, and 168).

Sustained CIDs were also assessed and defined as: a moderate-to-severe COPD exacerbation leading to study withdrawal, or an $\mathrm{FEV}_{1}$ decrease $\geq 100 \mathrm{ml}$ or an SGRQ total score increase $\geq 4$ units from baseline on two consecutive visits, or for $\geq 50 \%$ of all available subsequent visits. As the protocols from the studies mandated that patients be withdrawn from the study following a moderate-to-severe COPD exacerbation, the first incidence of a moderate-to-severe COPD exacerbation was also considered a component of sustained CID. In each study, adverse events (AEs) were monitored.

\section{Statistical Analysis}

Statistical comparisons were presented for UMEC/VI 62.5/25 mcg versus TIO. Trough $\mathrm{FEV}_{1}$ and SGRQ comparisons were analyzed using a repeated measures model including covariates of study, treatment, baseline score, smoking status, geographical region, day, day by baseline, and day by treatment. Comparisons of rescue-free days were analyzed using logistic regression with covariates of study, treatment, baseline percentage, smoking status, and geographical region. Comparisons of the time to a first or sustained short-term CID, and each individual component within these endpoints, were analyzed using a Cox proportional hazards model including covariates of study, treatment, smoking status at screening, and geographical region.

\section{Compliance with Ethics Guidelines}

All procedures followed in the studies were in accordance with the ethical standards of the responsible committee on human experimentation (institutional and national) and with the Helsinki Declaration of 1964, as revised in 2013. Informed consent was obtained from all patients for being included in the studies.

\section{RESULTS}

\section{Study Population}

The ITT population in the UMEC/VI 62.5/25 and TIO group consisted of 1747 patients, of which 533 patients formed the MN subgroup of interest. The other treatment arms (UMEC 125.25, VI 25, and UMEC 125) comprised 850 patients in total but were not included in the analysis as they are unlicensed medications and doses. Although certain patient demographics such as age, sex, and reversibility were similar in the ITT and MN populations, there were some notable differences (Table 1). More patients in the MN subgroup were current smokers than in the ITT population $(65 \%$ vs. $52 \%$ in patients treated with UMEC/VI and $60 \%$ vs. $51 \%$ in patients treated with TIO). As expected, more patients in the $\mathrm{MN}$ subgroup had moderate COPD (GOLD stage II) than severe/very severe COPD (GOLD stage III/IV), and post-albuterol \% predicted $\mathrm{FEV}_{1}$ was higher in the $\mathrm{MN}$ population. 
Table 1 Patient demographics and baseline characteristics

\begin{tabular}{|c|c|c|c|c|}
\hline & \multicolumn{2}{|c|}{ ITT population } & \multicolumn{2}{|c|}{ MN population } \\
\hline & $\begin{array}{l}\mathrm{UMEC} / \mathrm{VI} \\
62.5 / 25 \\
(N=878)\end{array}$ & $\begin{array}{l}\text { TIO } \\
(N=869)\end{array}$ & $\begin{array}{l}\text { UMEC/VI } \\
62.5 / 25 \\
(N=275)\end{array}$ & $\begin{array}{l}\text { TIO } \\
(N=258)\end{array}$ \\
\hline Age, years, mean (SD) & $63.0(8.6)$ & $63.4(8.7)$ & $61.7(8.6)$ & $62.3(8.7)$ \\
\hline Male, $n(\%)$ & $596(68)$ & $594(68)$ & $194(71)$ & $165(64)$ \\
\hline Current smoker at screening ${ }^{\mathrm{a}}, n(\%)$ & $457(52)$ & $439(51)$ & $180(65)$ & $155(60)$ \\
\hline Smoking pack-years ${ }^{\mathrm{b}}, n(\%)$ & $45.1(25.6)$ & $46.1(27.0)$ & $47.1(25.6)$ & $49.5(30.1)$ \\
\hline Reversible to albuterol ${ }^{\mathrm{c}, \mathrm{d}}, n(\%)$ & $243(28)$ & $248(29)$ & $94(34)$ & $77(30)$ \\
\hline Post-albuterol\% predicted $\mathrm{FEV}_{1}$ Mean $(\mathrm{SD})^{\mathrm{e}}$ & $47.0(13.1)$ & $47.0(12.99)$ & $50.9(12.27)$ & $50.1(12.84$ \\
\hline \multicolumn{5}{|l|}{ GOLD stage, $n^{\mathrm{f}_{*}}(\%)$} \\
\hline II & $393(45)$ & $385(44)$ & $154(56)$ & $141(55)$ \\
\hline III & $372(42)$ & $375(43)$ & $103(38)$ & $94(37)$ \\
\hline IV & $111(13)$ & $106(12)$ & $17(6)$ & $22(9)$ \\
\hline \multicolumn{5}{|l|}{ ICS use at screening ${ }^{\mathrm{g}}, n(\%)$} \\
\hline Yes & $443(50)$ & $445(51)$ & 0 & 0 \\
\hline \multicolumn{5}{|l|}{ Exacerbation history $^{\mathrm{h}}, n(\%)$} \\
\hline $\begin{array}{l}\text { Required corticosteroid and/or antibiotic } \\
\text { (without hospitalization) }\end{array}$ & $193(22)$ & $215(25)$ & $57(21)$ & $45(17)$ \\
\hline Required hospitalization & $73(8)$ & $80(9)$ & $18(7)$ & $20(7)$ \\
\hline \multicolumn{5}{|c|}{$\begin{array}{l}F E V_{1} \text { forced expiratory volume in } 1 \mathrm{~s}, G O L D \text { global initiative for chronic obstructive lung disease } \\
\text { corticosteroid, } I T T \text { intent to treat, } M N \text { maintenance-naïve, } S D \text { standard deviation, } T I O \text { tiotropium, UMEC } \\
V I \text { vilanterol } \\
\text { a Patient reclassified as current smoker if smoked within } 6 \text { months } \\
\text { b Smoking pack-years }=\text { (number of cigarettes smoked per day/20) } \times \text { number of years smoked } \\
\text { c Reversibility was defined as an increase in } \mathrm{FEV}_{1} \text { of } \geq 12 \% \text { and } \geq 200 \text { ml following administration of alb } \\
\text { d ITT population: UMEC/VI, } n=876 \text {; TIO, } n=863 \\
\text { e ITT population: UMEC/VI, } n=876 \text {; TIO, } n=866, \mathrm{MN} \text { population: UMEC/VI, } n=274 \text {; TIO } n= \\
\text { f UMEC/VI, } n=873 \text {; TIO, } n=859 \\
\text { g ICS use was defined as those patients who were currently taking ICS medications at the screening visit } \\
\text { h Patients experiencing } \geq 1 \text { exacerbation during the } 12 \text { months prior to screening }\end{array}$} \\
\hline
\end{tabular}

\section{Efficacy}

Trough $\mathrm{FEV}_{1}$ : In both the $\mathrm{MN}$ and ITT populations, UMEC/VI was associated with statistically significant improvements compared with $\mathrm{TIO}$ in trough $\mathrm{FEV}_{1}$ from day 2. At day 169 mean improvements in trough $\mathrm{FEV}_{1}$ from baseline were significantly greater for
UMEC/VI versus TIO in both populations' least squares (LS) mean difference [95\% confidence interval (CI)]: $\mathrm{MN}$ population: $146 \mathrm{ml}$ (102-189); $P<0.001$; ITT population: $95 \mathrm{ml}$ (71-118), $P<0.001$ (Fig. 1).

Health-related quality of life: UMEC/VI and TIO provided mean improvements ( $\geq 4$-unit decrease) from baseline in total SGRQ score, in 


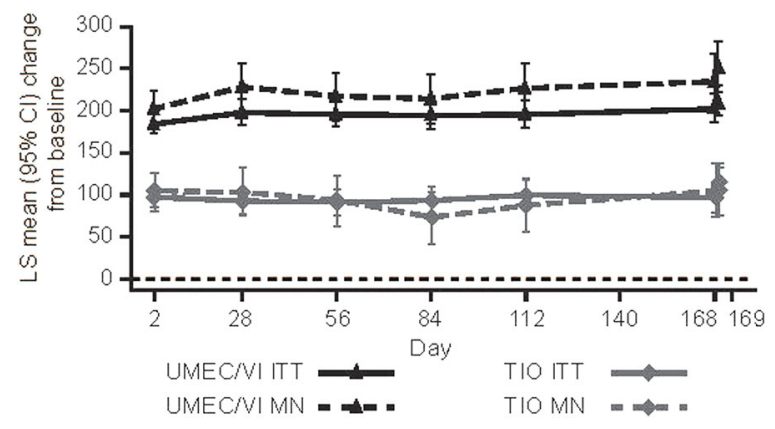

Fig. 1 Trough $\mathrm{FEV}_{1}$ changes over time in the ITT and $\mathrm{MN}$ populations. $C I$ confidence interval, $F E V_{1}$ forced expiratory volume in $1 \mathrm{~s}, I T T$ intent to treat, $L S$ least squares, $M N$ maintenance-naïe, $T I O$ tiotropium, UMEC umeclidinium, $V I$ vilanterol

both the MN and ITT populations, throughout the study (Fig. 2). Improvements versus baseline were numerically greater in the $\mathrm{MN}$ population compared with the ITT population for both treatment regimens at all visits. SGRQ total scores were significantly improved with UMEC/VI versus TIO in the ITT population on day 28 ( -2.25 units, $95 \% \mathrm{CI}:-3.26$ to -1.23 ; $P<0.001)$ and day 84 ( $-1.63: 95 \%$ CI: -2.76 to $-0.49 ; P=0.005)$, but not on day $168(-0.93$; 95\% CI: -2.19 to $0.33 ; P=0.149$ ) (Fig. 2). In the smaller $\mathrm{MN}$ population, the SGRQ treatment differences were in favor of UMEC/

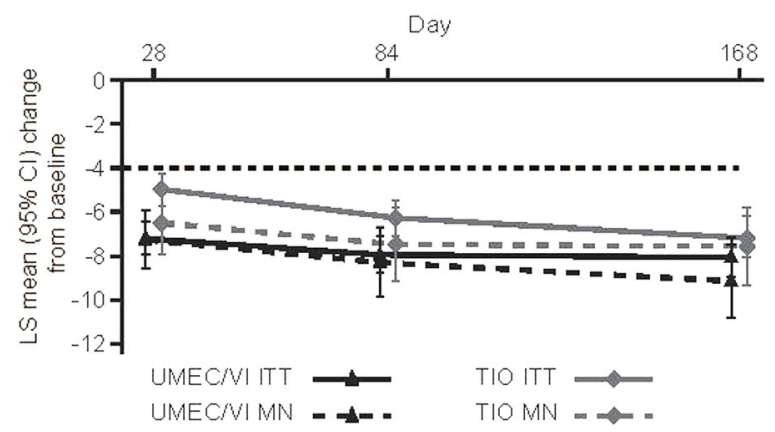

Fig. 2 SGRQ total score mean change from baseline in the ITT and MN populations. CI confidence interval, ITT intent to treat, $L S$ least squares, $M C I D$ minimal clinically important difference, $M N$ maintenance-naïve, $S G R Q \mathrm{St}$ George's respiratory questionnaire, TIO tiotropium, UMEC umeclidinium, $V I$ vilanterol
VI at all time points, but were not significant (Fig. 2).

The odds of being an SGRQ responder ( $\geq 4$-unit decrease) versus a non-responder was significantly greater with UMEC/VI treatment compared with TIO treatment at days 28 and 84 in the ITT population (OR: 1.3 at both time points; $P=0.007$ day $28 ; P=0.009$ day 84 ), but was not significantly different in the $\mathrm{MN}$ population (Table S1). At day 168, the odds of being a responder versus a non-responder were not significantly different between treatment groups in either the MN or ITT populations (Table S1).

Rescue medication use: The percentage of patients achieving a response in rescue-free episodes was significantly greater with UMEC/ VI compared with TIO in both the ITT [ $46 \%$ vs. 36\%; OR: 1.5 (95\% CI: 1.2-1.9)] and MN [47\% vs. 37\%; OR: 1.5 (95\% CI: 1.0-2.2)] populations (Table 2). The mean number of puffs/day over weeks 1-24 was improved for UMEC/VI versus TIO in both the ITT and MN populations [difference (ITT): -0.5 (95\% CI: -0.8 to -0.3 ) puffs/day; $P<0.001 ;(\mathrm{MN}):-0.5$ (95\% CI: -0.9 to 0.0$) ; P=0.066]$.

The proportion of patients with a short-term composite CID was lower with UMEC/VI treatment versus TIO treatment in both populations (MN population: $41 \%$ vs. $55 \%$; ITT population: $41 \%$ vs. $56 \%$ ). The risk of a first CID was reduced with UMEC/VI compared with $\mathrm{TIO}$ in the $\mathrm{MN}$ population $[\mathrm{HR}=0.66$ (0.51-0.85); $P=0.001$ ] (Fig. 3). Similar results were observed for UMEC/VI treatment versus TIO in the ITT population [HR $(95 \% \mathrm{CI})=0.62$ (0.54 to 0.71); $P<0.001$ ] (Fig. 3).

When the individual components of a first short-term CID were assessed, a significant reduction in the risk of deterioration in lung function was observed for UMEC/VI treatment versus TIO in both the MN and ITT 
Table 2 Summary and analysis of rescue medication use

\begin{tabular}{|c|c|c|}
\hline Rescue use, puffs/day, weeks 1-24 & UMEC/VI & TIO \\
\hline ITT population, $n$ & 776 & 764 \\
\hline LS mean change from baseline (SE) & $-2.0(0.09)$ & $-1.40(0.10)$ \\
\hline UMEC/VI vs. TIO, OR (95\% CI) & $-0.5(-0.8 \text { to }-0.3)^{*}$ & \\
\hline MN population, $n$ & 241 & 225 \\
\hline LS mean change from baseline (SE) & $-1.6(0.18)$ & $-1.1(0.18)$ \\
\hline UMEC/VI vs. TIO, OR (95\% CI) & $-0.5(-0.9 \text { to } 0.0)^{*}$ & \\
\hline \multicolumn{3}{|l|}{ Rescue-free episodes } \\
\hline ITT population, $n^{\star}$ & 776 & 764 \\
\hline Patients achieving increase ${ }^{\mathrm{a}}, n(\%)$ & $357(46)$ & $273(36)$ \\
\hline UMEC/VI vs. TIO, OR (95\% CI) & $1.5(1.2 \text { to } 1.9)^{*}$ & \\
\hline MN population, $n^{\ddagger}$ & 241 & 225 \\
\hline Patients achieving increase, $n(\%)$ & $114(47)$ & $84(37)$ \\
\hline UMEC/VI vs. TIO, OR (95\% CI) & $1.5(1.0 \text { to } 2.2)^{\S}$ & \\
\hline
\end{tabular}

$C I$ confidence interval, ITT intent to treat, $L S$ least squares, $M N$ maintenance-naïve, $O R$ odds ratio, TIO tiotropium, $U M E C$ umeclidinium, $V I$ vilanterol

${ }^{*} P<0.001,{ }^{\dagger} P<0.01 ;{ }^{\circledR} P<0.05,^{\star} P=0.066$ for UMEC/VI vs. TIO

* $n$ is the number of patients with analyzable data at the current time point

a Patients demonstrating a treatment effect similar to 1 extra rescue-free month per year or 2 extra rescue-free weeks in 24 (a change from baseline $\geq 8.3 \%$ over weeks $1-24$ )
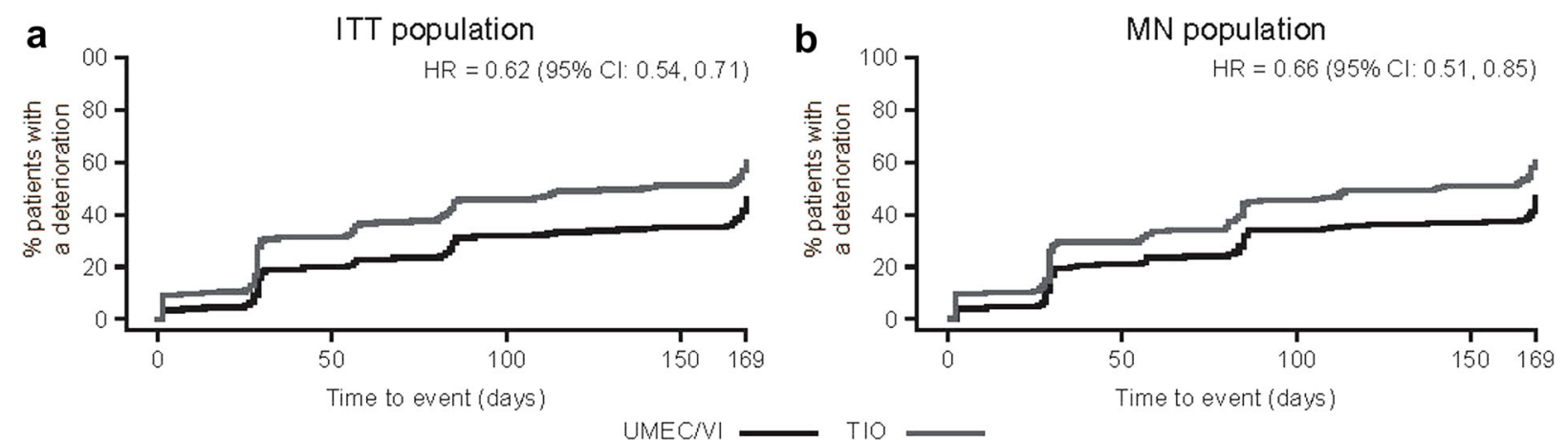

Fig. 3 Time to first CID in the a ITT and $\mathbf{b}$ MN populations. CID clinically important deterioration, ITT intent to treat, $M N$ maintenance-naïve, TIO tiotropium, UMEC umeclidinium, $V I$ vilanterol, $H R$ hazard ratio, $C I$ confidence interval

populations (Table 3). The risk of a CID on SGRQ total score was also significantly reduced with UMEC/VI treatment compared with TIO, but only in the ITT population
(Table 3). There was no significant difference between the treatment groups in the risk of a moderate-to-severe exacerbation in either population. 
Table 3 Summary and analysis of first deterioration events in the ITT and MN populations

\begin{tabular}{llll}
\hline Components of the first CID & UMEC/VI 62.5/25 & TIO & $\begin{array}{l}\text { Hazard ratio, UMEC/VI } \\
\text { vs. TIO } \\
\text { (95\% CI) }\end{array}$ \\
\hline ITT population, $n$ & 878 & 869 & \\
$\geq 100 \mathrm{ml}$ decrease in trough FEV 1 & $159(18)$ & $308(35)$ & $0.44(0.36 \text { to } 0.53)^{*}$ \\
$\geq 4$-unit SGRQ total score increase & $208(24)$ & $236(27)$ & $0.83(0.69 \text { to } 1.00)^{\dagger}$ \\
Moderate-to-severe COPD exacerbation & $56(6)$ & $54(6)$ & $1.02(0.70$ to 1.48$)$ \\
MN population, $n$ & 275 & 258 & \\
$\geq 100$ ml decrease in trough FEV & $53(19)$ & $93(36)$ & $0.44(0.32 \text { to } 0.62)^{*}$ \\
$\geq 4-$-unit SGRQ total score increase & $66(24)$ & $69(27)$ & $0.92(0.65$ to 1.29$)$ \\
Moderate-to-severe COPD exacerbation & $13(5)$ & $9(3)$ & $1.33(0.57$ to 3.13$)$ \\
\hline
\end{tabular}

Data presented as $n$ (\%) unless otherwise indicated

$C I$ confidence interval, $C I D$ clinically important deterioration, $C O P D$ chronic obstructive pulmonary disease, $F E V_{1}$ forced expiratory volume in $1 \mathrm{~s}$, ITT intent to treat, $M N$ maintenance-naïve, SGRQ St George's respiratory questionnaire, TIO tiotropium, $U M E C$ umeclidinium, $V I$ vilanterol

${ }^{*} P<0.001,{ }^{\dagger} P<0.05$

Risk of sustained CID: The proportion of patients with a sustained CID was approximately half of that observed for the first CID and was lower for UMEC/VI versus TIO in both the MN population (22\% vs. $30 \%$ ) and the ITT population ( $21 \%$ vs. $30 \%)$. The risk of a sustained CID was significantly reduced in the UMEC/VI treatment group versus the TIO treatment group, for both the $\mathrm{MN}$ and ITT populations [MN population: $\mathrm{HR}=0.69(0.49$ to 0.97$) ; P<0.05]$; ITT population: $\mathrm{HR}=0.64$ (0.53 to 0.77), $P<0.001$; (Table S2)].

Safety: Overall, the incidences of AEs were similar for the two treatment groups in both the ITT and MN populations, with nasopharyngitis and headache reported most frequently. One exception was a lower incidence of upper respiratory tract infection in the UMEC/VI treatment group compared with TIO in the MN population [ 2 vs. 10 patients ( $<1 \%$ vs. $4 \%)$ ]. The incidences of non-fatal serious AEs and fatal AEs were also similar between both populations (Table 4). Pneumonia and cardiovascular events occurred in $<1 \%$ in the UMEC/VI and TIO groups (in both populations).

\section{DISCUSSION}

This is the first analysis to compare the differences between UMEC/VI and TIO in a MN COPD population, looking at indices of both improvement and deterioration including the novel composite endpoint of short-term CID, which encompasses multiple elements and measurement of short-term worsening in COPD advocated in current guidelines.

In this analysis, UMEC/VI provided improvements in trough $\mathrm{FEV}_{1}$ from baseline compared with TIO in both the MN and ITT populations, with the largest magnitude of effect seen in $\mathrm{MN}$ patients. The greater treatment effect on trough $\mathrm{FEV}_{1}$ in the $\mathrm{MN}$ population could, in part, be related to reduced confounding because of background ICS therapy, but may also be due to patients with less impaired lung function having greater 
Table 4 Summary of AEs

\begin{tabular}{|c|c|c|c|c|}
\hline & \multicolumn{2}{|c|}{ ITT population } & \multicolumn{2}{|c|}{ MN population } \\
\hline & $\begin{array}{l}\text { UMEC/VI } \\
(\boldsymbol{N}=\mathbf{8 7 8})\end{array}$ & $\begin{array}{l}\text { TIO } \\
(N=869)\end{array}$ & $\begin{array}{l}\text { UMEC/VI } \\
(N=275)\end{array}$ & $\begin{array}{l}\text { TIO } \\
(N=258)\end{array}$ \\
\hline \multicolumn{5}{|c|}{ AEs reported by $\geq 3 \%$ of patients on any treatment, $n(\%)$} \\
\hline Nasopharyngitis & $63(7)$ & $62(7)$ & $18(7)$ & $15(6)$ \\
\hline Headache & $80(9)$ & $55(6)$ & $20(7)$ & $15(6)$ \\
\hline Back pain & $27(3)$ & $28(3)$ & $8(3)$ & $4(2)$ \\
\hline Cough & $25(3)$ & $26(3)$ & $5(2)$ & $8(3)$ \\
\hline Upper respiratory tract infection & $17(2)$ & $26(3)$ & $2(<1)$ & $10(4)$ \\
\hline \multicolumn{5}{|l|}{ AEs of special interest } \\
\hline Cardiovascular events (any) & $2(<1)$ & $2(<1)$ & 0 & $1(<1)$ \\
\hline Pneumonia & $2(<1)$ & $6(<1)$ & 0 & $1(<1)$ \\
\hline \multicolumn{5}{|l|}{ On-treatment non-fatal SAEs } \\
\hline Any event, $n(\%)$ & $42(5)$ & $35(4)$ & $8(3)$ & $11(4)$ \\
\hline \multicolumn{5}{|l|}{ Fatal AEs ${ }^{a}$} \\
\hline Any event, $n(\%)$ & $4(<1)$ & $7(<1)$ & $3(1)$ & $2(<1)$ \\
\hline \multicolumn{5}{|c|}{$\begin{array}{l}A E \text { adverse event, } C O P D \text { chronic obstructive pulmonary disease, } I T T \text { intent to treat, } M N \text { maintenance-naive, } S A E \text { serious } \\
\text { adverse event, } T I O \text { tiotropium, } U M E C \text { umeclidinium, } V I \text { vilanterol } \\
\text { a Deaths were attributable to the following: } I T T \text { : cardiac arrest, cardiac failure, COPD, and hemorrhagic stroke in the } \\
\text { UMEC/VI group; cardiac failure, pulmonary embolism, respiratory arrest, respiratory failure, upper gastrointestinal } \\
\text { hemorrhage, sudden death, and pancreatic carcinoma in the TIO group. } M N \text { : Cardiac arrest, hemorrhagic stroke, and } \\
\text { COPD in the UMEC/VI group; respiratory arrest and respiratory failure in the TIO group }\end{array}$} \\
\hline
\end{tabular}

capacity to benefit from increased bronchodilator therapy [14]. Consistent with this, a recent study assessing the efficacy of TIO plus olodaterol versus TIO monotherapy also demonstrated improvements from baseline in trough $\mathrm{FEV}_{1}$ that tended to be greater in patients with less severe COPD and who were LAMA or LABA naïve [4].

This study also assessed the effect of UMEC/ VI and TIO treatment on the composite endpoint of short-term CID, which is designed to address clinically important early signs of deterioration in lung function, health status, and/or COPD exacerbations. A recent study has demonstrated the dual bronchodilator therapy may reduce the risk of short-term CID and potentially provide greater airway stability compared with monotherapy [15].

One additional potential advantage of the CID approach is that it provides a means to assess symptomatic patients, including $\mathrm{MN}$ patients at risk of deterioration at an early stage in the course of COPD, potentially providing useful information on how to prevent deterioration and maintain stability or when to escalate therapy.

This analysis demonstrated that UMEC/VI reduced the risk of a first composite short-term CID compared with TIO to a similar extent in both the ITT and MN populations. These 
preliminary results in $\mathrm{MN}$ patients provide additional insight into the potential benefits of optimizing lung function in low-risk symptomatic patients with COPD. The improved bronchoprotection seen with dual bronchodilators versus monotherapy in both the MN and ITT cohorts in this analysis may be indicative of more prolonged disease stability. Further, validation of this endpoint is ongoing to better understand the long-term consequences of short-term CID on morbidity and mortality over several years of follow-up [16].

Previous studies have demonstrated an accelerated lung function decline in patients with moderate compared with severe and very severe COPD; therefore, optimizing bronchodilator treatment at an earlier stage may provide longer term benefits $[1,2,17]$. In support of this, early maintenance treatment with TIO was shown to be associated with long-term sustained benefits in the 4-year UPLIFT study, with a slower decline in lung function and HRQoL [3, 18]. In a previous publication, which examined time to a first CID with UMEC/VI versus TIO and placebo in both GOLD B and D subgroups, no apparent differences were found in the magnitude of treatment benefit on the incidence of CID based on levels of lung function impairment or disease severity at baseline [15]. The current study focused on patients from three similar studies with a large proportion of symptomatic COPD patients (all mMRC $\geq 2$ ), $55 \%$ and $45 \%$ of the ITT and MN subgroups, respectively, presenting with severe lung function impairment at baseline. The current findings are commensurate with the earlier study by Singh and colleagues [15], highlighting that reducing the risk of a first CID is as likely in low and high risk patients and when using dual bronchodilators as first- or second-line therapy.
It is therefore important that the early use of dual therapy was compared with monotherapy in this $\mathrm{MN}$ population.

Safety data were similar for both the $\mathrm{MN}$ and ITT populations when comparing UMEC/VI and TIO. A low number of serious AEs [including few cardiac events and incidences of pneumonia ( $\leq 2 \%$ in any treatment group)] and a low mortality rate $(\leq 1 \%)$ were reported with each treatment in each population. As such, the data present no increased safety concern for the earlier use of UMEC/VI compared with LAMA monotherapy in the course of COPD treatment. This is also supported by the results of a recent network meta-analysis that demonstrated no increased safety signal for LAMA/LABAs versus either mono LAMAs or LABAs [19].

One key limitation of the study is the retrospective nature of the findings. Additionally, only patients with moderate-to-severe breathlessness were included in the original clinical studies comparing UMEC/VI and TIO, and all patients had a low exacerbation risk. Consequently, it is possible that patients who are less symptomatic than those studied here could be managed on monotherapy. Also, exacerbations as a deterioration parameter had limited potential to feature strongly in this short-term analysis. Therefore, a longer follow-up may mean that exacerbations feature more prominently in the CID endpoint in low-risk patients receiving bronchodilators without concurrent ICS. Whilst the occurrence of short-term CID has been linked with long-term poor outcomes, further validation of the CID endpoint in prospective trials of increased duration are needed to better understand long-term outcomes in COPD with dualversus mono-bronchodilator therapy. 


\section{CONCLUSIONS}

The efficacy and safety data presented here support the use of dual-bronchodilator therapy as the first-line maintenance treatment option in patients with moderate-to-severe breathlessness and a low risk of exacerbations. The impact of dual- versus mono-bronchodilator therapy on the natural history of COPD requires validation with long-term prospective studies.

\section{ACKNOWLEDGEMENTS}

This study was funded by GSK (GSK analysis: 202066) using data from three clinical trials that were also funded by GSK: NCT01316900/ DB2113360, NCT01316913/DB2113374, and NCT01777334/ZEP117115. Article processing charges and the open access fee for this article were funded by GSK.

Editorial assistance in the preparation of the manuscript (in the form of writing assistance, assembling tables and figures, collating author comments, grammatical editing, and referencing) was provided by Natasha Thomas and Joanne Ashworth of Fishawack Indicia, Ltd., and was funded by GSK.

I. Naya is the guarantor of the paper, taking responsibility for the integrity of the work as a whole, from inception to published article.

I. Naya and L. Tombs were involved in the conception and design of the study. AA and MRMY were involved in the acquisition of data. All authors contributed to the data analysis and interpretation. All named authors meet the International Committee of Medical Journal Editors (ICMJE) criteria for authorship for this manuscript, contributed to the writing and reviewing of the manuscript, take responsibility for the integrity of the work as a whole, and have given final approval to the version to be published.

Disclosures. M. R. Maleki-Yazdi has acted as a consultant for Almirall, AstraZeneca, Boehringer Ingelheim, Forest Laboratories, GlaxoSmithKline (GSK), Novartis, Merck, Ono Pharmaceuticals, and Pfizer.

D. Singh has received sponsorship to attend international meetings, honoraria for lecturing or attending advisory boards and research grants from various pharmaceutical companies including Almirall, AstraZeneca, Boehringer Ingelheim, Chiesi, Genentech, GSK, Glenmark, Johnson \& Johnson, Merck, NAPP, Novartis, Pfizer, Skyepharma, Takeda, Teva, Theravance, and Verona.

A. Anzueto acted as a consultant for AstraZeneca, Boehringer Ingelheim, Forest Laboratories, GSK, Novartis, and Pfizer.

I. Naya is an employee of GSK and holds stocks/shares in GSK.

W. A. Fahy is an employee of GSK and holds stocks/shares in GSK.

L. Tombs is a Contingent worker at GSK.

Compliance With Ethics Guidelines. All procedures followed in the studies were in accordance with the ethical standards of the responsible committee on human experimentation (institutional and national) and with the Helsinki Declaration of 1964, as revised in 2013. Informed consent was obtained from all patients for being included in the studies.

Open Access. This article is distributed under the terms of the Creative Commons Attribution-NonCommercial 4.0 International License (http://creativecommons.org/licenses/ by-nc/4.0/), which permits any noncommercial use, distribution, and reproduction in any 
medium, provided you give appropriate credit to the original author(s) and the source, provide a link to the Creative Commons license, and indicate if changes were made.

\section{REFERENCES}

1. Jenkins CR, Jones PW, Calverley PM, et al. Efficacy of salmeterol/fluticasone propionate by GOLD stage of chronic obstructive pulmonary disease: analysis from the randomised, placebo-controlled TORCH study. Respir Res. 2009;10:59.

2. Troosters T, Sciurba FC, Decramer $M$, et al. Tiotropium in patients with moderate COPD naive to maintenance therapy: a randomised placebo-controlled trial. NPJ Prim Care Respir Med. 2014;24:14003.

3. Troosters T, Celli B, Lystig T, et al. Tiotropium as a first maintenance drug in COPD: secondary analysis of the UPLIFT ${ }^{\circledR}$ trial. Eur Respir J. 2010;36:65-73.

4. Ferguson GT, Flezar M, Korn S, et al. Efficacy of tiotropium + olodaterol in patients with chronic obstructive pulmonary disease by initial disease severity and treatment intensity: a post hoc analysis. Adv Ther. 2015;32:523-36.

5. Dransfield MT, Bailey W, Crater G, et al. Disease severity and symptoms among patients receiving monotherapy for COPD. Prim Care Respir J. 2010;20:46.

6. Jones PW. St. George's respiratory questionnaire: MCID. COPD. 2005;2:75-9.

7. Westwood M, Bourbeau J, Jones PW, et al. Relationship between FEV1 change and patient-reported outcomes in randomised trials of inhaled bronchodilators for stable COPD: a systematic review. Respir Res. 2011;12:40.

8. Wilke S, Spruit MA, Wouters EF, et al. Determinants of 1-year changes in disease-specific health status in patients with advanced chronic obstructive pulmonary disease: a 1-year observational study. Int J Nurs Pract. 2015;21:239-48.

9. Donohue JF. Minimal clinically important differences in COPD lung function. COPD. 2005;2:111-24.
10. GOLD. Global strategy for the diagnosis, management and prevention of chronic obstructive pulmonary disease http://www. goldcopd.com/. Accessed Aug 2015.

11. Maleki-Yazdi MR, Kaelin T, Richard N, Zvarich M, Church A. Efficacy and safety of umeclidinium/ vilanterol $62.5 / 25 \mathrm{mcg}$ and tiotropium $18 \mathrm{mcg}$ in chronic obstructive pulmonary disease: results of a 24-week, randomized, controlled trial. Respir Med. 2014;108:1752-60.

12. Decramer M, Anzueto A, Kerwin E, et al. Efficacy and safety of umeclidinium plus vilanterol versus tiotropium, vilanterol, or umeclidinium monotherapies over 24 weeks in patients with chronic obstructive pulmonary disease: results from two multicentre, blinded, randomised controlled trials. Lancet Respir Med. 2014;2:472-86.

13. Celli BR, MacNee W. Standards for the diagnosis and treatment of patients with COPD: a summary of the ATS/ERS position paper. Eur Respir J. 2004;23:932-46.

14. Renard D, Looby M, Kramer B, et al. Characterization of the bronchodilatory dose response to indacaterol in patients with chronic obstructive pulmonary disease using model-based approaches. Respir Res. 2011;12:54.

15. Singh D, Maleki-Yazdi MR, Tombs L, Iqbal A, Fahy B, Naya I. Prevention of clinically important deteriorations in COPD with umeclidinium/ vilanterol. Int $\mathrm{J}$ Chron Obstruct Pulmon Dis. 2016;11(1):1413-24.

16. Naya I, Tombs L, Jones P. Short-term clinically important deterioration predicts long-term clinical outcome in copd patients: a post hoc analysis of the torch trial. Thorax. 2015;70:A1-254.

17. Tantucci C, Modina D. Lung function decline in COPD. Int $\mathrm{J}$ Chron Obstruct Pulmon Dis. 2012;7:95-9.

18. Decramer M, Celli B, Kesten S, et al. Effect of tiotropium on outcomes in patients with moderate chronic obstructive pulmonary disease (UPLIFT): a prespecified subgroup analysis of a randomised controlled trial. Lancet. 2009;374:1171-8.

19. Oba Y, Sarva ST, Dias S. Efficacy and safety of long-acting beta-agonist/long-acting muscarinic antagonist combinations in COPD: a network meta-analysis. Thorax. 2016;71:15-25. 